\title{
Development and Implementation of the Integrated Marketing Communications Concept
}

\author{
Tatjana Cvetkov Čikošev ${ }^{1 *}$
}

1 NIS a.d., Belgrade, Serbia

\begin{abstract}
Understanding consumers' needs implies creating an adequate offering, which leads to good and sustainable relations over time. Consumers, under the influence of (new) technologies, change their habits, attitudes and behaviour in the usage of certain product or service as well as the way they communicate. Analysis of the effects of created communication on the brand through developing IMC model is the main objective of this paper. Considering consumers' demographic structure, not only the points at their path to purchase, usage or recommendation, the effects among different groups will be analyzed. Questions that are important for this paper are about awareness of brands in the category, noticeability of certain ways of communication, and the influence of that communication on behaviour is measured. The goal of every communication is sales and repeated sales, but in that process potential users should be introduced to brand, create a need and want to use that brands, to be satisfied, loyal and be its ambassadors. Beside usage of the results of primary research, desk method of collecting and analysing is also used, in order to have detailed insight of certain aspects that are related to the objective of this paper. The results of conducted research indicate that the implementation of integrated marketing communications leads to additional sale and better brand positioning, as well as company positioning in the market. Additionally, effective integrated communications positively influence brand positioning and consumers 'satisfaction is in positive relation with the repeated purchase of the brand.
\end{abstract}

Key words: integrated marketing communications, brands, positioning, customer experience, consumer behaviour

JEL Classification: M31

\section{INTRODUCTION}

In today's world, consumers, brands, and the media are changing, fundamentally some would say. Those changes put marketers in front of many challenges. How we interact and how we communicate is directly under the influence of the technology and the Internet and its development. With "epidemic" of new media, consumers change, and how they use and utilise different media sources, which consequently have influence on brand choice timing, place and way of choosing. Consumers attention is divided, as they willingly (or not) multitask. Consumers are not passive receivers of brand information, through so-called traditional media, print or TV, which accumulate in their memory for usage once they need that information, as it was supposed before. They are now active seekers of information when in need - using all available

\footnotetext{
*E-mail: tatjana.cvetkov@nis.eu
} 
means - different search engines, (mobile) browsers, blogs, forums, brand websites (Porcu, Del Barrio-Garcia, Kitchen, 2017).

Marketers are now, under the influence of these new ways of communicating, creating personalised content of the message, personalise time and location of conveying this message, and utilising more (as much as it is needed) media to achieve set communication objectives. The other side is more complex customer journeys and the focus on customer experience (Domazet, Stošić, Lazić, 2018). Customers may now have interactions with firms through multiple channels and media, almost countless number of touch points.

The objective of this paper is to identify customer journey, critical touch points and adequate communication as an answer to it, that leads to profitable customer behaviour. The model of integrated marketing communication that is used as a base for this paper is presented as a conceptual framework. Therefore the idea is to empirically test it on one brand, and try to answer some of the questions emerged in the original work. One of the issues are the effects of the communication, which option(s) is the best fit for achieving set goals on the customer journey (Domazet, Đokić, Milovanov, 2018). Or, how all the communication options may be integrated to maximise the effects. Authors of the conceptual framework, Batra and Keller (2016), propose, among others, checking the role of brand web page, positive and negative sides, and if it works in growing trust and emotions. Beside this, the paper is analyzing consumer behavior on the lubricant market, as well as outcomes of created communication.

\section{INTEGRATED MARKETING COMMUNICATION}

\section{Communication}

Marketing communications are the means by which firms attempt to inform, persuade and remind consumers - directly or indirectly - about the products and brands they sell (Kotler \& Keller, 2009). As shown in Table 1, eight major modes of communication make the marketing communications mix: the first half of the Table, advertising, sales promotion, events and PR, are considered as more mass media types of communications. The other half, direct marketing, interactive marketing, WOM and personal selling are 1 on 1, more personal modes of communication (Keller 2009). Marketing communications is the narrator of the brand story, it tells or shows consumers the story about the product - where, when, how and why is used, as well as who is using it, the typical user. Also, it tells a story about the company and their values. Using the tools of marketing communications companies make relations of their brands and places, events, other brands, other people. Experiences are created, feelings are provoked, and all other things attributed to the brand, company, product or service (Domazet, 2012). Beside aforementioned, marketing communications can build communities, both online and off-line (Faškova \& Kretikova, 2015).

Table 1. Major communication types

(1) Advertising -promotion of ideas, goods or services by an identified sponsor in any form that is paid and is not personal

(2) Sales promotion - the objective is to encourage trial or purchase of product, service, brand, supported by diverse incentives, for limited (short) time

(3) Events and experiences - in order to create interactions on daily basis or for special occasion firms design programs or sponsor different events

(4) Public relations and publicity - the main goal is to promote or protect a company's image or its products. services, brands 
(5) Direct marketing - using different means of communication (mainly digital - e-mail, and other electronic means of communication, but also mail, telephone) to speak directly with customers and prospects.

(6) Interactive marketing - different to direct marketing, as main goal is to engage customers to interact, and raise awareness, improve image or elicit sales of products and services. Also, these activities and programs are online

(7) Word-of-mouth marketing - any recommendation, information about user (buyer) experience, mouth -to-mouth (thus it may be written, electronic, or really verbal) communications

(8) Personal selling - face-to-face interaction - presentation of product/service/brand, Q\&A, ordering with potential buyer

Source: Kotler \& Keller (2009)

The communication environment changed and it not easy at all for marketing communications (Domazet \& Neogradi, 2018). The media environment has changed dramatically - new media, technology driven, grow, while on the other side traditional advertising media such as TV, radio, magazines and newspapers are losing their position(s) (Chang \& Thorson, 2004). Everything is changed - the time, the place, and how consumers process communications, and even their choice is to process them at all. In this new media environment, the consumer is the one who has control. Consumers not only have more choices of media to use, they also have a choice about whether and how they want to receive commercial content (Domazet, Stošić \& Hanić, 2016). The broadband Internet connections, ad-skipping digital video recorders, multi-purpose (smart) mobile phones and portable music and video players and all other changes in consumers lives, enforce marketers to rethink many of their traditional practices almost daily (Kaplan \& Koval, 2003; Kiley, 2005). Put in its simplest form, integrated marketing communications (IMC) is the bringing together of all marketing communications activities working towards the same goal. Integrated marketing communications are the coordinated, consistent means by which firms attempt to inform, incent, persuade, and remind consumers, directly or indirectly, about the products and brands. (Pickton \& Broderick, 2004). Integrated marketing communications is a process which involves the management and organization of all individuals and organizations involved in the marketing communications process within and external to the organization, in the analysis, planning, implementation and control of all marketing communications contacts, media, messages and promotional tools focused at selected target audiences in such a way as to derive the greatest enhancement and coherence of marketing communications effort in achieving predetermined product and corporate marketing communications objectives (Pickton \& Broderick, 2004).

Integration of marketing communications should be or lead to synergy, which is described as the $2+2=5$ phenomenon. In terms of marketing communications, that means that bringing together the various types and forms of marketing communications in a mutually supportive and enhancing way then the resulting 'whole' is more than the simple sum of its parts (Hanić, Domazet \& Simeunović, 2012). On the other side, lack of integration of marketing communications elements must be acknowledged - not only that various promotional tools have to perform independently of the other elements but also that, collectively, the total effort can be counter-productive (McGrath, 2010). Integration is not an easy process and cannot be effortlessly be achieved, but when it is reached, the 4Es and 4Cs of IMC create the synergistic benefits of integration (Pickton \& Broderick, 2004). IMC should be enhancing (improve; intensify), economical (least cost in the use of financial and other resources), efficient (doing things right), effective (doing the right things). The 4Cs of integrated marketing communications are coherence (logically connected), consistency (not self-contradictory), continuity (connected and consistent over time), complementary communications (producing a balanced whole).

Integration is not easily achieved, and while the problems of integration are not impossible, they are significant for a variety of reasons. IMC is discouraged by mindset of individuals 
involved (fear of change and loss of control) and their abilities (esp. managers), classifications and language, the structure of organizations, sense of superiority, the scale of the task, adequacy of budgets, and dimensions of integration.

\section{The IMC conceptual framework}

The marketing communications environment is transformed by technological advances and other factors and becomes a new challenge and/or opportunity to the ones that practice it. For example, great versatility and precision of digital media is huge potential, but on the other side, they are challenging for integration (Domazet \& Stošić, 2013). Marketers need new tools and ways of thinking that can provide structure to an increasingly complex communications environment if they want to use these new media opportunities. To better understand how to develop and deliver fully integrated communication programs in today's changing marketing world, Batra and Keller (2016) reviewed academic research and proposed conceptual framework. Result of their academic research review is following five main themes:

1. Decision journey nowadays significantly differs to the one it was in the past - IMC programs need to be more carefully designed and implemented to maximize results, esp. having in mind media and messages, that should be stage appropriate

2. Every communication option has its own strengths and weaknesses and generates specific (different to other types) of effects on consumer knowledge and behaviour along consumers' decision journeys. Additionally, marketers' ability to aim for the specific outcome with greater precision increases by new media options

3. There is a myriad of interaction and synergy across communications. Different types of information, different communications and all their combination and sequence, create relations that lead to change consumer knowledge and behaviour in meaningful ways.

4. Once they identify changes in knowledge and behaviour (direct or indirect) caused by different communications, marketers can choose those communication options that are most likely to collectively achieve brand objectives.

5. Digital communication options, hardly present in the past, influence consumers directly as well as indirectly and the way they interact with many other digital or nondigital communication options.

A conceptual framework is presented in Figure 1. It shows the combination of two conceptual models in order to assist in the development and delivery of IMC programs. On one side there is consumer and communication outcomes - the knowledge and understanding of the consumer, the context, and the content - everything that "colors" the (desired) outcome (Kerr \& Patti, 2015). The communications matching model should commend the best-aligned media and messaging options, by bearing in mind the specific objectives and desired outcomes at different stages of the consumer's journey on one side and the different media features (Batra \& Keller, 2016). The communication optimisation model is about effectiveness and efficiency - all proposed communication options are evaluated to ensure that maximal collective effects result (Batra \& Keller, 2016).

By considering communication matching and integration in detail, the two communications models offer a comprehensive top-to-bottom view of marketing communications. The framework offered can help guide managerial thinking and academic research in several specific areas. For example, it may help understanding online versus offline communication, which media/messages are controlled by marketers versus the ones that consumers create and influence, digital versus nondigital differences, as it is broad and neutral regarding media.

When thinking about communication optimization model it is important to consider coverage (reach of the desired effectiveness of different communication options), contribution (is it affecting consumer positively, influencing each stage along their journey), communality 
(common associations across communication options?), cross-effect, conformability (is this appropriate answer to different consumers, their different characteristics and communication needs). Well-designed IMC program should perform well on these criteria. However, there are more opportunities to match communications to one another if more modalities are employed (audio, images, video...), to appeal to different audiences. (Batra \& Keller, 2016).

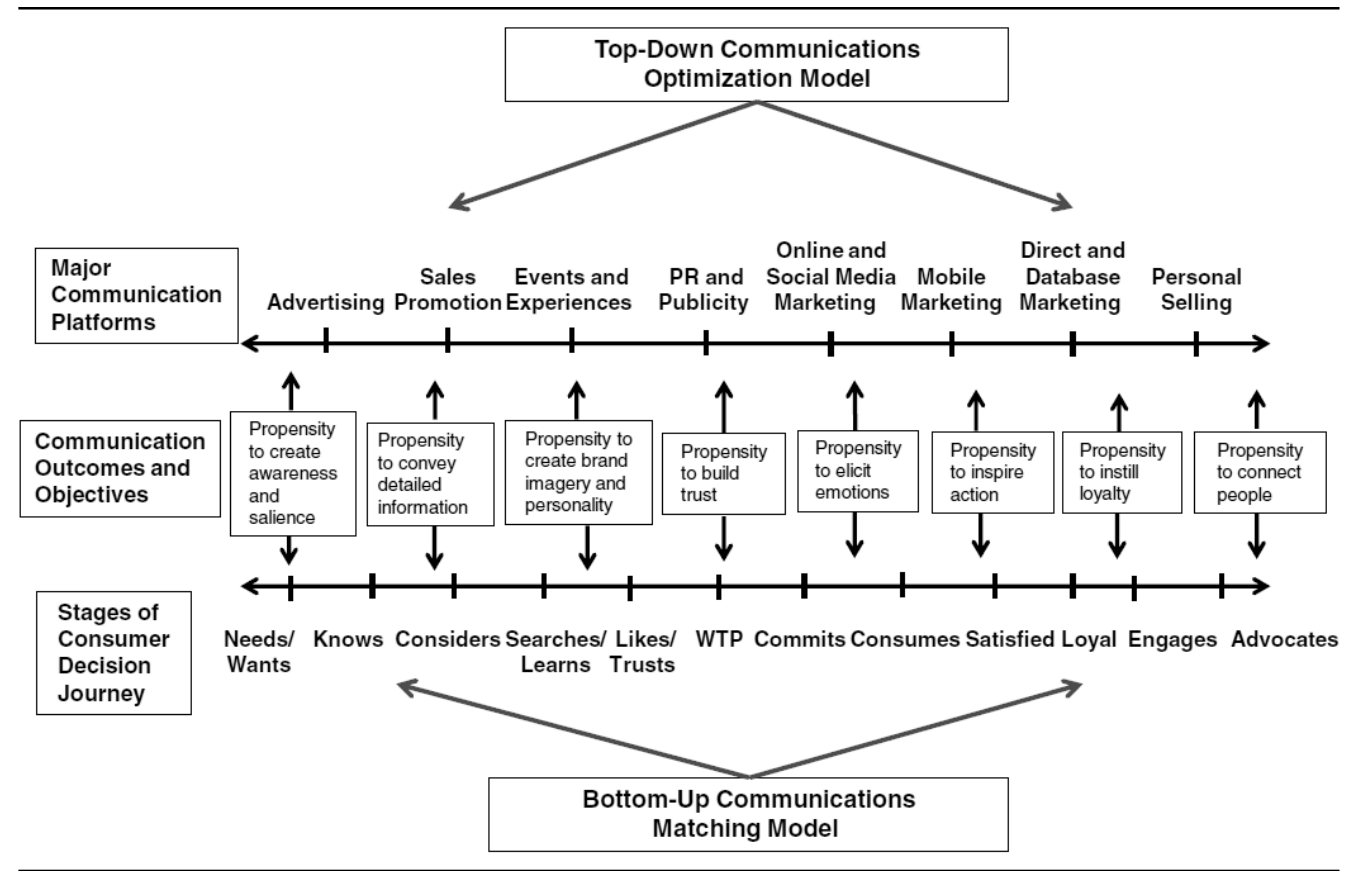

Figure 1. IMC Conceptual Framework

Source: Batra \& Keller (2016)

The communication matching model studies the needs/gaps in consumer knowledge and behaviours, compares the current position of different targeted consumer segments to where they need to be, relative to the brand's needs. Afterwards, suggests the most appropriate media combinations that should best meet these needs/gaps at each stage along the journey (Batra \& Keller, 2016). The journey consist of 12 steps - from having a need at a category level, knowing about (can recall and recognize), over active consideration, search for more information and building brand knowledge, liking and having trust, willing to pay (more) for it, having (high) desire to act, and consuming/using, to satisfaction, both attitudinal and behavioral loyalty, engagement and interaction, and advocating for this particular brand.

An emerging and increasingly recognized best practice in the area of brand and customer management is that experiences are emotional and emotions are multi-dimensional. There are two dimensions of primary interest - Valence (Was the experience good or bad? Answer shows what we often get right) and Arousal (Was the experience memorable or forgettable? Answer leads to what we often overlook). The more memorable and vivid an experience is, the stronger the emotional imprint it creates - and the higher that person's advocacy and resistance to switching to competitors (Robins, 2015). Identifying those aspects of the experience that leave an emotional imprint, leads to customer-centric insights on which attributes to promote, to drive loyalty and enhance customer lifetime value. According to Robins (2015), direct experiences create more positive and memorable experiences than indirect experiences. Owned and earned experiences (usage, WOM, in store, sponsoring, etc.) create more positive and memorable experiences than paid experiences. 


\section{THE EFFECTS OF CREATED COMMUNICATION}

\section{The Industry of lubricants}

Lubricant can be defined as a substance that reduces friction, not limited to that function, but also completing certain strict, specific demands. For example, modern motor oil has to lubricate surfaces, but at the same time has to have the cooling ability, corrosion protection, sealing, cleaning engine elements and it has to be thermally and oxidatively stable. Without those traits, it wouldn't be able to please the complex demands of the modern engine. Durability and reliability of a machines operation and of various mechanisms is greatly conditioned by the right selection and application of lubricant. Namely, poor lubricant selection or its wrong application are the cause of premature and rapid contact surface wear, permanent deformation and damage.

Lubricants are chosen specifically for different parts of a machine. So for example in motor vehicles, the engine is lubricated with motor oil, the transmission mechanism with transmission oil, certain bearings with lubricating grease and similar.

The task of motor oil in an engine is to:

- Lubricate the engine, reduce friction and wear of metal surfaces and moving parts when in contact

- Clean the internal engine parts from carbon black particles

- Seal the engine (cylinder - piston assembly), blocks the penetration of combustion glasses into the engine crankcase and it raises the engine compression

- Protect internal engine parts from corrosion

- Provide the correct engine operation in low as well as in high temperatures

- Secure added cooling

Demand for lubricants in the Balkan region has stabilised from 2015. In the period 2008-2013 was a drop and stagnation due to the economic situation. By the year 2025, a 10 percent growth in demand is expected (Mandakovic \& Novina, 2015). A significant qualitative structure change and a growth in demand of top of the line quality lubricants is expected in the region due to very strict environmental legislation and change and renewing the automobile transportation fleet. New industry technological solutions will also play a part on the qualitative change of the structure of lubricants. There are a total of 80 brands of small manufacturers. By the year 2030, a 46 thousand tons growth is forecasted in the Serbian market. Main market development growth factors are - Macroeconomics, Environmental protection and Sustainable development.

NISOTEC brand was presented to the Serbian market in 2008. as a result of NOVOLIN rebranding, produced in the NIS Oil refinery in Novi Sad. After the completion of a detailed market analysis of the Serbian and regional markets in 2010, a new market oriented strategy was adopted, a complete redesign of the label's visual identity and an advertising campaign was done under the "Simply better" slogan. The same year, NISOTEC brand became the general sponsor of Dusan Borkovic, who ended that season as the runner up of the European rally championship and in the general standings. There was a formation of the NISOTEC RACING TEAM. NISOTEC gets the leading position in the Serbian Market in 2012. That same year cooperation with Dusan Borkovic continues, which quickly lead to the realisation of both parties vision: NISOTEC as a champion of quality, confirmed by a quality and good design champion trophy, with plenty of gold medals at the Novi Sad agriculture fair, thus becoming a leader on the domestic market and NISOTEC RACING TEAM becoming a European champion. With the goal of following modern market tendencies, in 2013 there was a NISOTEC packaging rebranding done. Quality levels were differentiated based on the color of the packaging and oil types based on the label colors. An asortiman of NISOTEC lubricating grease was introduced. The distribution network and new sales channels was expanded in 2014 which led to an increase in market share of NISOTEC in the lubricant market, thus confirming the leading position in Serbia. New 
confirmation was received from engine and equipment manufacturers as well as OHSAS 18001:2007 quality certificate. Today, in this oil brand asortiman there is over 200 products in over 500 different packages, and all of them cover over 20 different range of application.

\section{Created communication}

Marketing support is an important component in a brand life, and in the case of lubricants and Serbian market, consist of several activities that lead to increase of brand awareness and loyalty, and ultimately, sales.

Generally speaking, all major communication types are used in order to reach set targets by the company. PR and publicity support every event and every sales promotion organized at NIS Petrol and Gazpromneft petrol station as well as other sales outlets covered by distributors. Among events, brand takes presence at fairs. Presence in digital media is through website (with information about promotions, trends... ), as well as an online program that help consumer choose the lubricants that are best suited for their vehicles. Also, advertising through Google (google search and google display) are part of the communication set for the brand. Having loyalty program "Sa vama na putu" makes usage of direct marketing possible - informing customers via e-mail, Viber messaging or SMS. Specifically, this year communication plan of activities, towards customers, had one new product launching and one new product packaging introduction, price promotion activities, presence at Agronomical fair in Novi Sad, as well as a campaign „MOJ AUTO VOLI NISOTEC“. All activities are noted in Table 2, together with both communication optimization and matching models, i.e. platforms and outcomes.

The idea of integration of marketing communication for this brand was always present, thus breakthrough is made by considering consumer journey of several personas. One type of users consider themselves as experts regarding their vehicle, and therefore the best lubricant. They read magazines and websites regarding this topic, they may be those who recommend others what to buy/use, but may not be loyal to brands, but to types of lubricants. They know when they need to change lubricants, and when in need, they search the net (and other offline sources, like auto magazines), visit some stores and always petrol station. They may be price sensitive, thus they like to consider themselves as smart shoppers. The main answer to their need is quality, not overpriced lubricant, nourishing their smart shopper image.

The other type is opposite to them, those who have no knowledge and don't need to know they rely on recommendation, mechanics and car service people mostly. For them, easy to find easy to use is most important. They either have to be able to buy the lubricant at the car service or somewhere where they usually go (supermarket, PS where they usually go, auto shop near car service...). Third group are those who constantly have to be assured that they are making the right decision, that the quality, price and other features are the right ones. For them, a good image and brand presence is very important. Forth group are the ones with the habit, who once made a decision what to buy and continue to follow the route. In a situation in which they buy a new car, with different engine and needs, they may change their habit, otherwise they are not easy to be reassured. Fortunately, they are behaving the same with the petrol station choice, so Nisotec has the opportunity to remind them of its presence and assure them of its quality and price. 
Table 2. IMC implementation for Nisotec

\begin{tabular}{|c|c|c|}
\hline Activity & $\begin{array}{l}\text { Top down } \\
\text { (communication optimization } \\
\text { model) }\end{array}$ & $\begin{array}{l}\text { Bottom up } \\
\text { (communication matching model) }\end{array}$ \\
\hline $\begin{array}{l}\text { NEW product launch - } \\
\text { NISOTEC ANTILED } \\
\text { Feb } 2018\end{array}$ & $\begin{array}{l}\text { Web campaign } \\
\text { Promotion at PS } \\
\text { Promotions with sampling } \\
\text { Direct marketing - messages (SMS, } \\
\text { VIBER) } \\
\text { PR }\end{array}$ & $\begin{array}{l}\text { Remind of need for the category, learn, } \\
\text { active consideration } \\
\text { Trial and work on trust } \\
\text { Improve awareness of this specific } \\
\text { product, as well as total brand } \\
\text { awareness }\end{array}$ \\
\hline $\begin{array}{l}\text { Price discount for } \\
\text { SNNP and Agro card } \\
\text { users } \\
\text { March } 2018\end{array}$ & $\begin{array}{l}\text { POS } \\
\text { Posters } \\
\text { Website } \\
\text { PR } \\
\end{array}$ & $\begin{array}{l}\text { Consideration and buying } \\
\text { Awareness growth }\end{array}$ \\
\hline $\begin{array}{l}\text { 85. international } \\
\text { agricultural fair in Novi } \\
\text { Sad } \\
\text { May } 2018\end{array}$ & $\begin{array}{l}\text { Event presence } \\
\text { Media conference } \\
\text { PR and publicity } \\
\text { Digital } \\
\text { SMS }\end{array}$ & $\begin{array}{l}\text { Awareness } \\
\text { Knowledge of brand } \\
\text { Trust } \\
\text { Satisfaction }\end{array}$ \\
\hline $\begin{array}{l}\text { New packaging of } \\
\text { NISOTEC AdBlue } \\
\text { June } 2018\end{array}$ & $\begin{array}{l}\text { PR } \\
\text { POS } \\
\text { Promotion } \\
\text { Web site } \\
\end{array}$ & $\begin{array}{l}\text { Awareness of the new possibility } \\
\text { Buying } \\
\text { Satisfaction }\end{array}$ \\
\hline $\begin{array}{l}\text { MOJ AUTO VOLI } \\
\text { NISOTEC } \\
\text { July } 2018\end{array}$ & $\begin{array}{l}\text { Radio campaign } \\
\text { Web campaign } \\
\text { Promotion an PS } \\
\text { PR }\end{array}$ & $\begin{array}{l}\text { Awareness (remind) } \\
\text { Buying } \\
\text { Satisfaction }\end{array}$ \\
\hline $\begin{array}{l}50 \% \text { discount for the } \\
\text { second pack of } \\
\text { NISOTEC Testerol } \\
\text { September } 2018\end{array}$ & $\begin{array}{l}\text { POS } \\
\text { brand web page } \\
\text { company FB and Instagram } \\
\text { PR }\end{array}$ & $\begin{array}{l}\text { Consideration and buying } \\
\text { Awareness growth }\end{array}$ \\
\hline $\begin{array}{l}\text { with Evro Diesel get } \\
\text { NISOTEC DIESEL LUB } \\
\text { (NIS Agro card users) } \\
\text { October } 2018\end{array}$ & $\begin{array}{l}\text { POS on target Petrol stations } \\
\text { SMS }\end{array}$ & $\begin{array}{l}\text { Not loose gas oil users, but turn them to } \\
\text { Euro Diesel trust } \\
\text { Awareness }\end{array}$ \\
\hline
\end{tabular}

Source: Nisotec communication plan, 2018

\section{The Effects on brand}

Five years ago, NIS GPN started with the brand tracking study, in order to unify and continuously track market dynamics - usage and attitudes of consumers regarding fuels, petrol stations and lubricants, as well as brands (awareness, usage, image, communication...). The insights obtained are used for decision making, strategic and marketing plans to keep and grow the current position. The sample consists of weekly drivers, 18-64 years old, who use a car as a main way of transportation.

One of the important questions is the place of purchase of lubricants, and it shows that habits are not easily changed - the share of stores that sell car parts is the same from wave to wave. Comforting is the fact that NIS petrol station succeed in keeping lubricants' buyers, i.e. those who buy lubricants at petrol station. 


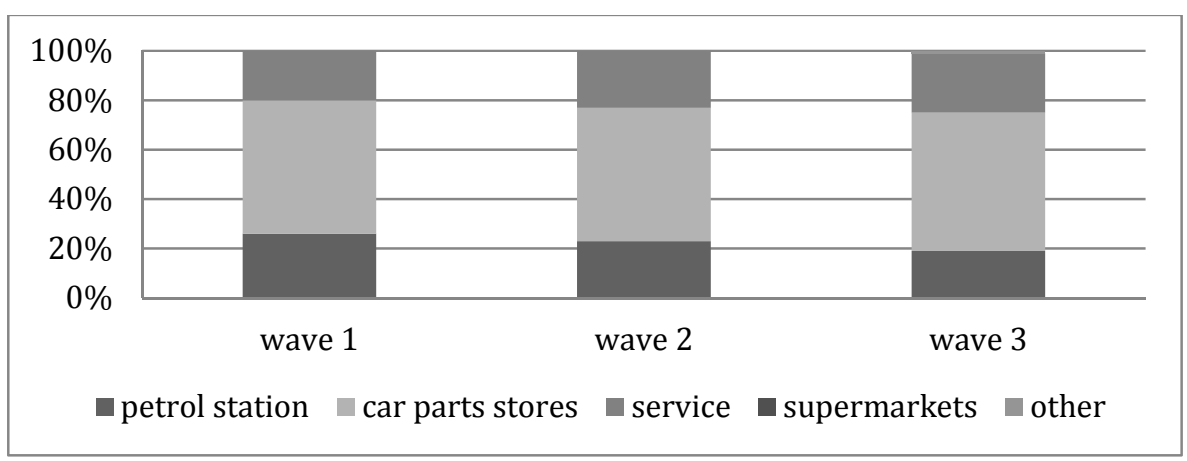

Figure 2. Purchase place - Where do you usually buy lubricants? Source: Brand Tracker Survey, 2013-2018, NIS, Serbia

Regarding the brand awareness, Nisotec reports an increase. One-half of drivers are aware of this brand, compared to $35 \%$ in the previous wave. The results of this year activities are to be measured by the end of this year.

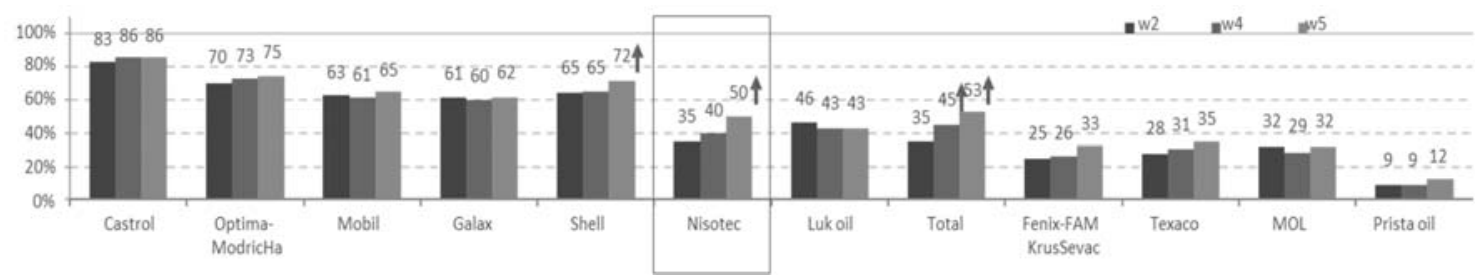

Figure 3. Total brand awareness - Which brands from the list do you know? Source: Brand Tracker Survey, 2013-2018, NIS, Serbia

This study also tracks the reasons which are important for decision making and shows growth of importance of price, quality and recommendations of mechanics. Users need to be assured that their choices are the best fit for their car for the budget they have.

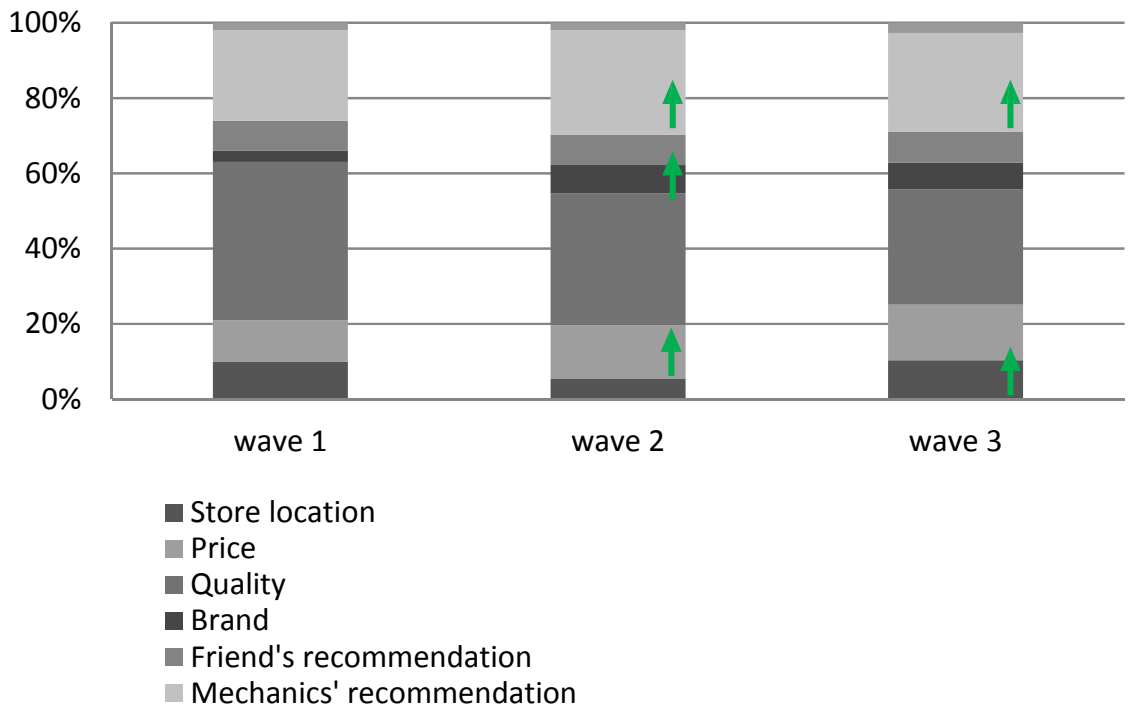

Figure 4. Decision making - Which source of information do you trust the most? Source: Brand Tracker Survey, 2013-2018, NIS, Serbia 
Another, performed among the visitors of Novosadski sajam in May 2018, shows which media platform has an influence on consumers, which one they have noticed Nisotec used, as well as the difference among users.

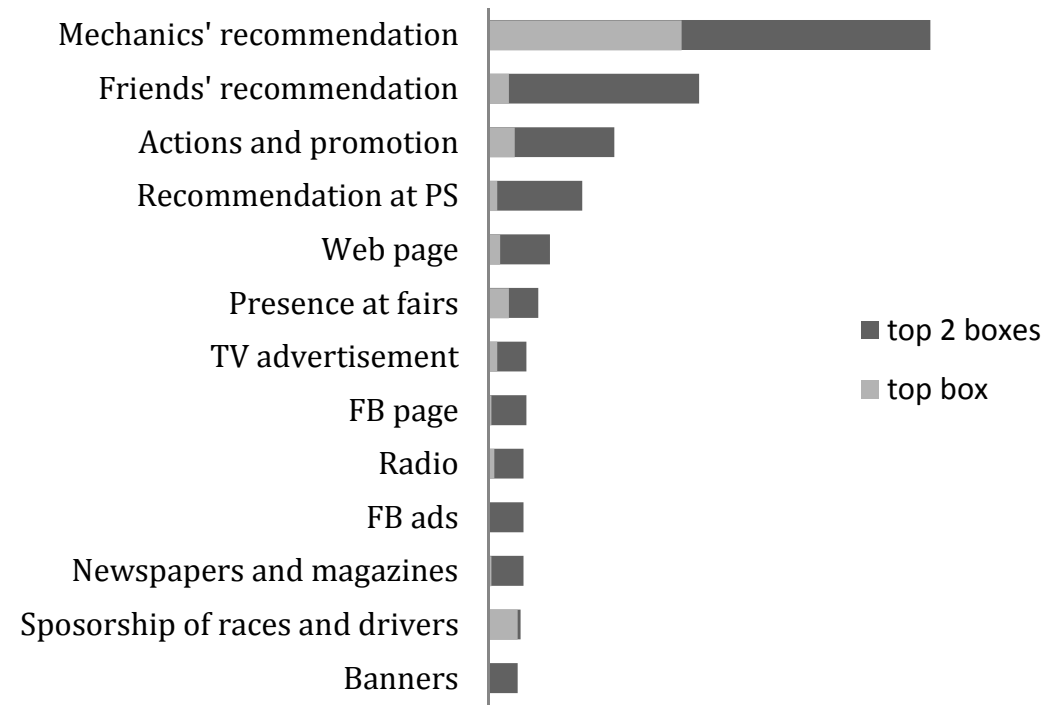

Figure 5. Influence on decision making

Source: NIS Survey at Novosadski sajam, may 2018, NIS

This study shows that the highest influence on decision making has mechanics' recommendation; even $80 \%$ says this communication has a high or highest influence on their decision. Another trustworthy sources are friends and family, especially mentioned by females, who are much less (mentally) involved in choosing lubricants. They are also more susceptible to information received from people at petrol stations, and also actions and promotions.

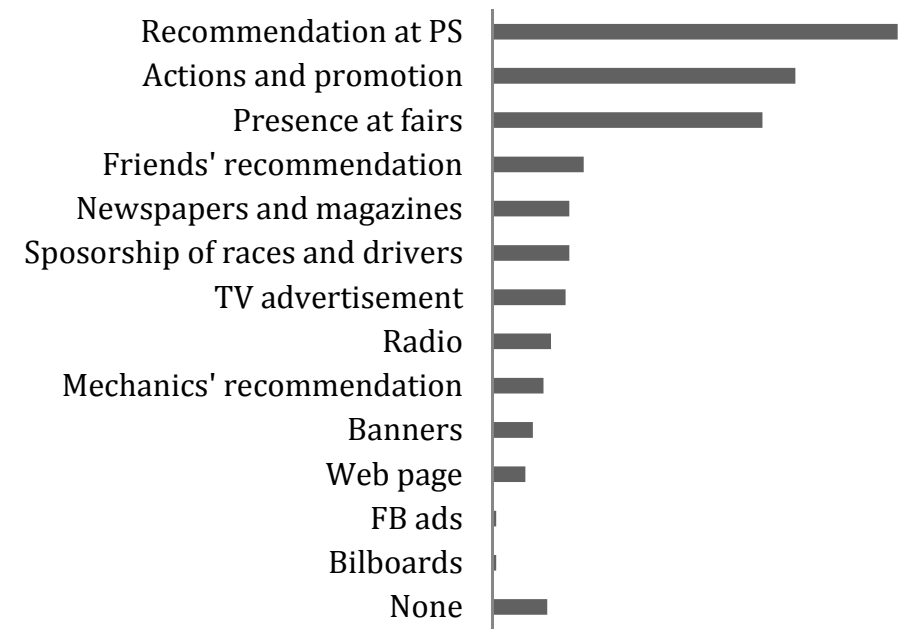

Figure 6. Nisotec communication noticed Source: NIS Survey at Novosadski sajam, May 2018, NIS 
Figure 6 shows that the majority has noticed communication at PS, i.e. recommendations, followed by actions and promotions. Interestingly, even being at fair, only $40 \%$ report noticing this kind of communication, most probably thinking of some other fair or not considering presence at fair as a communication. Some differences among subgroups are also noticed regarding this question - males more than females have the notion of seeing sponsorship of races and drivers, while females mention friends recommendations and seeing ads in print. The oldest group of respondents (older than 50 years) are less often mentioning seeing certain Nisotec communication, compared to younger users. Those aged 30-50 years more often mention noticing radio and print, as if they more often listen and read those media.

The effects can (and will be) measured by units sold, profit and profitability, but the results are collected once a year. Immediate actions, like price promotions, show results in an increase of sales during the action, but it's also important to know the yearly results. Year to date data show ambiguous information, and it's hard to tell what the yearly result will be.

\section{CONCLUSION}

The model of integrated marketing communication that is used as a base for this paper is applied, thus integration is not easily achieved. The effects of communication are measured and appreciated. The selection of which option(s) is the best fit for achieving set goals on the customer journey is not an easy process and is not fully conveyed - the customer journey way of thinking is one barrier, the budget constraints together with options available and acceptable for the company are another set of barriers. Still, even this level of integration of marketing communication leads to an additional sale and better positioning.

Seams that it's not enough to integrate activities for one brand, as the brand is part of a bigger system, and certain activities are not owned by the brand. That is, the structure of organization and adequacy of budget are barriers that slow down the process of integration.

The customer journey way of thinking is not fully accepted and implemented, it seems it takes more time, and more trials (and errors). On the positive side, some critical touch points are observed and communication as an answer to it, which leads to profitable customer behaviour, was applied.

\section{REFERENCES}

Batra, R., Keller, K.L. (2016). "Integrating Marketing Communications: New Findings, New Lessons, and New Ideas", Journal of Marketing, 80(6):122-145.

Brand Tracker Survey, 2013-2018, NIS, Serbia

Chang, Y., Thorson, E. (2004). "Television and web advertising synergies". Journal of Advertising, 33 (2), 75-84.

Domazet, I, Neogradi, S. (2018). “Digital Marketing and Service Industry: Digital Marketing in Banking Industry, International Monograph „Managing Diversity, Innovation, and Infrastructure in Digital Business“, Ed. Nilanjan Ray, IGI Global, Business Science Reference, Hershey, USA.

Domazet, I, Stošić, I, Hanić, A. (2016). "New technologies aimed at improving the competitiveness of companies in the services sector", International Monograph „Europe and Asia: Economic Integration Prospects“, CEMAFI International, Nice, France 2016, pp. 363-377.

Domazet, I. (2012). "Marketing komunikacije finansijskih organizacija", Institut ekonomskih nauka. 1-245.

Domazet, I., Đokić, I., Milovanov, O. (2018). "The Influence of Advertising Media on Brand Awareness", Management: Journal of Sustainable Business and Management Solutions in Emerging Economies, 23(1):13-22.

Domazet, I., Stošić, I. (2013). "Strengthening the competitiveness of Serbian economy and the corporate market restructuring." Economic Analysis, 46(3-4): 108-124. 
Domazet, I., Stošić, I., Lazić, M. (2018). "Competitive Relations in the Aftersales Market of Major Home Appliances in Serbia". Economic Analysis, 51(1-2): 47-59.

Fašková, V, Kretiková, E. (2015). "Online and offline consumer". Marketing Identity (2015)2:53-65.

Hanić, H, Domazet, I. \& Simeunović, I. (2012). "Efikasnost marketing komunikacija i efektivnost medija za različite ciljne grupe", International Scientific Conference: Management 2012. ICIM plus Beograd, pp. 791-796.

Kaplan Thaler, L. \& Koval, R. (2003). "Bang! Getting your message heard in a noisy world". New York: Currency in Keller K. L. (2009) Building strong brands in a modern marketing communications environment, Journal of Marketing Communications, 15 (2): 139-155

Keller, K. L. (2009). Building strong brands in a modern marketing communications environment, Journal of Marketing Communications, 15 (2): 139-155

Kerr, G. \& Patti, C. (2015). "Strategic IMC: From abstract concept to marketing management tool", Journal of Marketing Communications, 21(5):317-339.

Kiley, D. (2005). "Hey advertisers, TiVo is your friend". BusinessWeek, October 17, 97-8. in Keller K. L. (2009) Building strong brands in a modern marketing communications environment, Journal of Marketing Communications, 15 (2): 139-155

Kotler F. \& Keller K. L. (2009). “Marketing Management”, Pearson Prentice Hall, New Jersey.

Mandaković, R. \& Novina B. (2015). "Trendovi potrošnje, zahtjevi za kvalitetom kao i paradoksi na vrlo malom tržištu mazivu kao što su Hrvatska i susjedne zemlje", Goriva i maziva, 54(3), 187-200.

McGrath, J. M. (2010). "Using Means-End Analysis to Test Integrated Marketing Communications Effects". Journal of Promotion Management, 16(4):361-387.

NIS Survey at Novosadski sajam (2018), NIS, Serbia

Nisotec Communication plan (2018), NIS, Serbia

Pickton D. \& Broderick, A. (2004). "Integrated Marketing communications", Pearson Educations Ltd, London.

Porcu L., Del Barrio-García, S., \& Kitchen, P. (2017). "Measuring integrated marketing communication by taking a broad organisational approach: The firm-wide IMC scale", European Journal of Marketing, 51(3): 692-718.

Robins, D. (2015). "Customer Lifetime Value \& Loyalty in the New Consumer Economy", Total Customer Experience Philadelphia 2015

Article history: $\quad$ Received: November 13, 2018

Accepted: May 29, 2019 


\title{
Assessing Organisational Maturity in Predictive Analytics of Telecommunications Companies in the Republic of Macedonia
}

\author{
Kalina Trenevska Blagoeva $^{1}$ | Marina Mijoska ${ }^{1^{*}}$ \\ ${ }^{1}$ Ss.Cyril and Methodius University, Faculty of Economics - Skopje, Department for e-business, Republic of \\ Macedonia
}

\begin{abstract}
Data analytics and predictive analytics are among major trends companies are facing worldwide. In a highly digitalised environment, it is not only to question the usage of data analytics but how analytically mature organisations are. The goal of this paper is to assess organisational maturity in predictive analytics of telecommunications companies in the country.

In order to assess the level of organisational maturity in predictive analytics, we use Predictive Analytics Maturity Framework Assessment (PAMFA) (Capgemini, 2012), since it best describes maturity levels in the telecommunications sector. The method of analysis is based on interviewing managers with a questionnaire that guides respondents through all dimensions and levels proposed by the framework. According to the PAMFA five dimensions are analysed (Vision and strategy, Enablers, Competence, Deployment and Governance). For each dimension, four maturity levels are defined: Level 1: Impromptu, Level 2: Solo, Level 3: Ensemble and Level 4: Symphony (Capgemini, 2012).

Survey results confirmed that analysed companies fully understand the benefits of predictive analytics as a valuable source of gaining competitive advantage from data. The overall level of predictive analytics maturity is set between levels 2 or 3 for almost all dimensions.

This research is the first attempt to analyse organisational maturity in predictive analytics in the country. Its originality derives from the specific characteristics and development of the telecommunications sector. This sector is one of the most advanced service sectors in the country and hence represents a benchmark concerning digital transformation. Results of this survey provide useful information needed to design a roadmap for migrating towards higher maturity levels
\end{abstract}

Key words: organisational maturity, predictive analytics, predictive analytics maturity framework, telecommunications sector, Republic of Macedonia

JEL Classification: M19, L96

\section{INTRODUCTION}

Companies in all industries worldwide are using and benefiting from data analytics. Data analytics, especially big data analytics, advanced analytics, and predictive analytics, are among the major trends for 2017 companies worldwide are facing (Gartner, 2017). But, in spite of how powerful data analytics is, almost every organisation of every size is currently struggling with the challenges associated with building a proper analytics team and becoming a data-driven

*Corresponding author, e-mail: mijoskam@yahoo.com 
organisation. In the literature, there are a variety of explanations about what a data-driven company is and how an organisation can become one. An organisation where every individual can use data to improve decision-making and has ubiquitous access to the needed data can be considered as a data-driven company. There is no doubt that more companies will attempt to drive value and revenue from their data (Forester, 2017).

"Predictive analytics is a branch of the advanced analytics which is used to make predictions about unknown future events and uses many techniques from data mining, statistics, modelling, machine learning, and artificial intelligence to analyse current data to make predictions about future" (www.predictiveanalyticstoday.com). Predictive analytics provide analysing large amounts of data with different variables; it includes clustering, decision trees, market basket analysis, regression modelling, neural nets, genetic algorithms, text mining, hypothesis testing, and decision analytics (Mishra and Silakari, 2012). The goal is to go beyond knowing what has happened to providing a best assessment of what will happen in the future (https://www.forbes.com).

Data and analytics are also changing the nature of industry competition. The most significant changes are reported in high tech, media and telecom, and consumer and retail (McKinsey, 2016).

The ability to derive new insights from data using analytics techniques can enhance the decision-making process in companies. In today's analytics economy, in which data science is increasingly adopted by companies across all industries, it is not only to question the usage of data analytics but how analytically mature organisations are since the higher levels of analytical maturity provides better perspectives. In this sense, analytical maturity refers to organisations being able to get their business to its optimal potential by using predictive analytics. Using the maturity model can provide an understanding of the current state and help management form a strategy of what level of capability is desired in order to support the achievement of organisations objectives.

The telecommunications sector has seen momentous growth over the past decades and continues to be a critical force for growth, innovation, and disruption across multiple industries/countries. As a whole, the telecommunications industry generates upwards of 1 trillion euro in service revenues each year (https://www.statista.com/). The 54 telecommunications companies on the 2018 Forbes Global 2000 list claim more than \$3.4 trillion in assets and totalled nearly $\$ 1.5$ trillion in revenue last year (www.forbs.com). While in the past revenue was essentially sourced from a traditional landline and wireless services, today the range of products and services available in this industry is persistently increasing, offering further opportunities for revenue creation. The telecommunications industry is competing on analytics and embracing the new science of winning by investing in data science capabilities within the enterprise. These companies use predictive analytics for Analytical Customer Relationship Management (ACRM), fraud reduction, bad debt reduction, price optimisation, call center optimization, etc. In the study published by Ernst \& Young "Global telecommunications study: navigating the road to 2020", participants scored "improving big data and analytics capabilities" as very important in order to boost their organisational agility, with nearly $40 \%$ of respondents selecting it as a priority. Consumer behavior has changed significantly in the last five years. Consumers are shifting to applications like WhatsApp, Facebook Messenger, Snapchat, and Instagram rather than calling and texting. According to Stephan Gatien, General Manager of Telecommunications Business, SAP, the core services of telcos - text, voice, and data - are actually evaporating and the revenue associated with these services is evaporating as well. The big challenge in this industry is to determine how to offset the degradation of this revenue coming from text, voice, and data to a certain extent, by buying new services that will be relevant to subscribers. In the article. "Turning Data Into Insights: How Digitization Creates New Opportunities For The Telecommunications Industry, Julie Stoughton, the head of Telecommunications Marketing and Communications at SAP, stated that telecommunications 
companies are trying to reinvent themselves and stay relevant in the digital era. This has led to two major trends. First, companies are focused inward on their customer experience. They need to retain their most valuable customers and secondly, telcos are looking outward. They're considering how they can monetize the enormous volume of IoT data currently in their possession. There is no doubt that data analytics is not going to be neglected as a valuable tool for achieving that reinvention, not only for telecommunications companies but other service companies as well (Stoughton, 2018)

The telecommunications industry is area specific industry regarding predictive analytics use. This counts for the telecommunications sector in the Republic of Macedonia as well. This sector is one of the most advanced service sectors in the country and hence represent a benchmark concerning digital transformation.

In line with global trends, the telecommunications market in the country is developing rapidly, particularly in the mobile segment. Telecommunications in the Republic of Macedonia include radio, television, fixed and mobile telephones, and the Internet. According to the latest report of Agency of electronic communications of the Republic of Macedonia -AEC, the telecommunications market in the country is fully dominated by two companies (Makedonski Telekom and One. VIP) in all segments of the market (mobile, internet, fixed lines).

According to the data of the same report, in 2017,_the mobile operators' share in the mobile telephony market per number of active subscribers shows that Makedonski Telekom's share was $47.97 \%$, while One. Vip Operator's share was $49.57 \%$. The market share of mobile operators in the Republic of Macedonia by revenue generated from the provision of mobile communication services on the retail market is as follows: Makedonski Telekom has the largest market share at $52.56 \%$, while One. Vip Operator has a market share of $47.21 \%$, with a third operator having an insignificant share of $0.23 \%$. The market shares were calculated for the total revenue, which represents the sum of revenues arising from call initiation service, monthly subscription, data transfer, terminal equipment, SMS, MMS, roaming (traffic, SMS and data), and other revenues. The operators' share in the total number of active subscribers to broadband and narrowband internet access via mobile network $(2 \mathrm{G} / 3 \mathrm{G} / 4 \mathrm{G})$ states that One.VIP Operator has a market share of 52.18\%, Makedonski Telekom has a market share of $46.51 \%$, while the third operator has an insignificant market share of $1.31 \%$ (www.aek.mk).

\section{METHODOLOGY AND RESULTS}

According to the latest Data and Analytics Global Executive Study and Research Report (2018) prepared by MIT Sloan Management Review, organisations can outperform by making use of data from multiple sources. These organisations are considered innovative and analytically mature.

Data Analytics in companies matures differently with regards to different aspects/dimensions and different parts of an organisation (departments). In practice, the maturity path of an analytical organisation is not linear in all dimensions and departments. It has a more complex trajectory which is not synchronised nor by dimension or sector/department. According to Lismont (2017) "it is not unfamiliar that analytics is differently propagated throughout companies as they mature with a larger focus on department-wide or organisation-wide analytics and a more advanced data governance policy". (Lismont, 2017).

But, what analytically mature organisation means and how one organisation can become innovative and analytically mature. Different authors and consulting groups propose different analytics maturity models/frameworks in order to reach a predefined analytical maturity level. In the literature, one of the latest research representing a summary of the existing analytics maturity models is one of Chen and Nath (2018). According to their research, numerous maturity models have emerged recently, following the proliferation of the predictive analytics tools development. Chen and Nath (2018) suggest that business analytics maturity models can 
be categorized by the following determinants: technology, organization, capability, and impact focused.

One of the latest is the Analytic Processes Maturity Model (APMM) for evaluating the analytic maturity of an organisation (Grossman, 2018). The APMM identifies analytic-related processes in six key process areas, defined as: 1) building analytic models; 2) deploying analytic models; 3) managing and operating analytic infrastructure; 4) protecting analytic assets through appropriate policies and procedures; 5) operating an analytic governance structure; and 6) identifying analytic opportunities, making decisions, and allocating resources based upon an analytic strategy. Based upon the maturity of these processes, the APMM framework of Grossman (2018), organizations can differ i.e. reach five maturity levels defined as: level 1 organizations that can build reports level 2 -organizations that can build and deploy models; level 3 - organizations that have repeatable processes for building and deploying analytics; level 4 -organizations that have consistent enterprise-wide processes for analytics; and level 5 enterprises whose analytics is strategy driven. This model is based upon the Capability Maturity Model - CMM that is the basis for measuring the maturity of processes for developing software created by Software Engineering Institute, Carnegie Mellon University.

Another approach which provides estimation of analytics maturity i.e. analytical maturity levels differs organizations in three major categories based on their relative level of sophistication in adopting analytics i.e. 1) the Analytically Challenged organizations display limited analytical capabilities; 2) Analytical Practitioners largely use analytics to track and support performance indicators; and 3) Analytical Innovators incorporate analytics into virtually every aspect of their strategic decision-making, including gleaning data from a variety of sources such as direct measurement and sensors, industry data, and third parties (Ransbotham and Kiron, 2018, p.7).

According to the defined methodology, in order to determine the relative analytics proficiency of an organization, it is suggested to calculate the Analytics Core Index, based on the organization's core analytics capabilities in three major areas like: (1) ingesting data (capturing, aggregating, and integrating data); (2) analyzing data (descriptive analytics, predictive analytics, and prescriptive analytics); and (3) applying insights (disseminating data insights and incorporating insights into automated processes). In detail. the Analytics Core Index is calculated by assessing how effectively the organisation performs these seven analytics-related tasks and activities defined like 1. Capturing data, 2. Aggregating/integrating data, 3. Using descriptive analytics, 4. Using predictive analytics, 5. Using prescriptive analytics, 6. Disseminating data insights and 7. Incorporating analytics insights into automated processes (Ransbotham and Kiron, 2018, p.9). The measurement process is based on a five-point scale ranging from very ineffective to very effective. The Analytics Core Index score represents the sum of the responses to the seven questions, scaled to a range from 0 to 100 . Higher levels of analytical maturity are associated with higher levels of customer engagement, which in turn is associated with higher scores on the Analytics Core Index, which in turn is associated with greater use of diverse data sources. This means that organizations that make effective use of a wide range of data sources - from different types of technologies and different types of entities, such as customers, vendors, competitors, and publicly available sources - are more likely to use analytics to generate higher levels of customer engagement and gain a competitive advantage than organisations that use fewer sources of data. (Ransbotham and Kiron, 2018, p.9).

According to Lismont et al., (2016), the application of analytics in organisations generally differs with regards to five different aspects like: data, enterprise or organisation, leadership, targets or techniques and applications, and the analysts who apply the techniques themselves. In their research, they found that the analytics organisation in companies matures with regards to these aspects. Moreover, analytics is differently propagated throughout companies as they mature with a larger focus on department-wide or organisation-wide analytics and a more advanced data governance policy (Lismont et al., 2016). 
In our survey in order to assess the level of organisational maturity in predictive analytics, we use the Predictive Analytics Maturity Framework Assessment (PAMFA) (Capgemini, 2012), since it best describes maturity levels in the telecommunications sector. The method of analysis is based on interviewing managers with a questionnaire that guides respondents through all dimensions and levels proposed by the framework. In different business units within the same organisation, there are different maturity levels. For that reason, managers from different organisational sectors were approached and interviewed. According to the PAMFA five dimensions are analysed (Vision and strategy, Enablers, Competency, Deployment and Governance). For each dimension, managers were asked to choose the appropriate level of usage out of four available maturity levels: Level 1: Impromptu, Level 2: Solo, Level 3: Ensemble and Level 4: Symphony. This framework can serve as a roadmap for moving the organisation towards achieving its predictive analytics goals. The suggested framework which defines analytics adoption level of an organisation and its environment is illustrated in Figure 1.
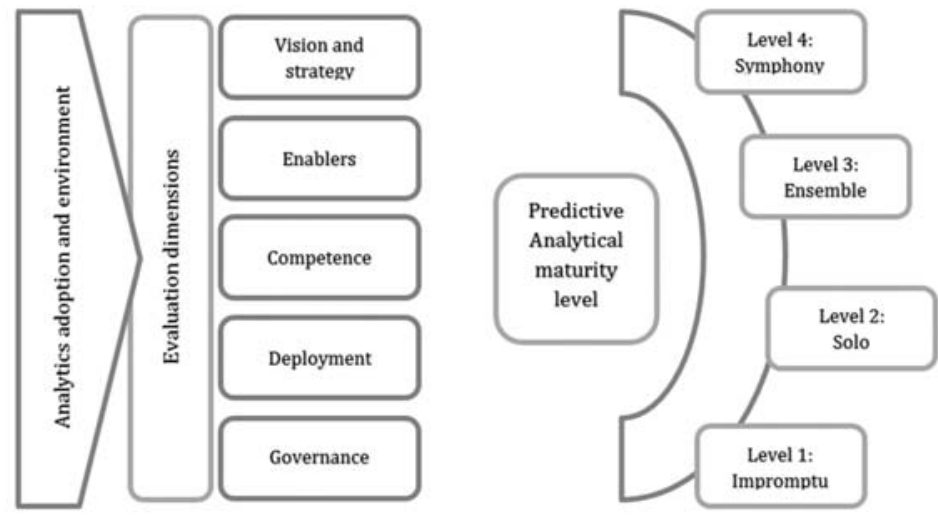

Figure 1. The PAMFA - dimensions and maturity levels

Source: Capgemini. 2012. "Measuring Organisational Maturity in Predictive Analytics: the First Step to Enabling the Vision", p.8.

According to the defined methodology, the five different aspects/dimensions of predictive analytics maturity are assessed. The first dimension is Vision and strategy. It is rare today for an organisation to develop software and information systems, without striving to use the data in best way. In this sense, having an analytics vision and strategy is very important, as the long term decisions an organisation makes about how it uses its data is needed. By defining maturity level of this dimension, the companies can write a broad "analytical map" in which the current level of the organisation will be stated, accompanied with the vision of the future wanted level. The roadmap can help in harmonising predictive analytics incentives with the organisation's high-level strategic goals.

It demonstrates where legitimisation, or execution of extra activities, is required. PAMFA looks at the current predictive analytics strategy, distinguishing any gaps and key enablers required for execution. Having a vigorous methodology set up makes it conceivable to prioritise analytics initiatives based on enterprise level business imperatives, not departmental ones.

The second measurement is called - Enablers, and it alludes to discovering how prepared the company's environment is to adopt or pursue predictive analytics. PAMFA examines the data condition, legacy solutions, analytics process, and technology and support arrangements. It likewise survey the association's comprehension of predictive analytics and its impression of the advantages. Among the empowering enablers considered in the framework are an information framework that suits predictive analytics needs and a justified portfolio of applications. 
The third dimension is Competence. This implies that organisations ought to have a full understanding of all current predictive analytics projects, and of parts where analytics could be used further on.

Next is Deployment. This measurement estimates the organisations capacity to convey predictive analytics and coordinate it into business processes which is a basic part of predictive analytics maturity. The central matter predictive analytics is to power is the decision making capability of the organisation.

The last, fifth dimension in the PAMFA is Governance. Governance is a regularly disregarded yet fundamental part of predictive analytics. Therefore, it is essential to look at the organisation's modelling lifecycle management and its administration of model precision and pertinence.

For every one of these measurements, four maturity levels are characterized. Level 1 is called Impromptu. At this level, sporadic and secluded analytic capability results from impromptu undertakings done by a solitary administrator or speciality unit. The second dimension is named Solo. Level 2 is separated into two sub-levels: Amateur Solo, implying that predictive analytics abilities and procedures exist for the most part at an individual dimension, and are not natural to the organisation, and Professional Solo which is a brilliance inside a silo. Predictive analytics processes, capacities and environment meet up to address business issues adequately, yet just for individual tasks. Level 3 is named Ensemble. On this level, one can perceive predictive analytics activities crosswise over business functionalities, with certain procedures being made together. The last, most developed level is Symphony level, where well-organised, company's wide activities apply analytics for achieving business advantage.

This framework can fill in as a guide for moving the organisation towards accomplishing its predictive analytics objectives. PAMFA is structured not exclusively to distinguish the present dimension of predictive analytics development, yet additionally to find the company's Ideal Analytics Maturity Level (IAML). The IAML is the dimension that would empower the firm both to capitalise on existing assets and furthermore to put ideally in extra assets, so as to accomplish key objectives and infer greatest business benefits.

The results of the survey confirm that analysed companies fall somewhere around level 2 or 3 for almost all dimensions. More precise, results for each dimension are shown in the table below.

Table 1: Survey results

\begin{tabular}{|l|c|c|c|c|c|c|c|c|c|c|}
\hline & \multicolumn{2}{|c|}{$\begin{array}{c}\text { Vision and } \\
\text { strategy }\end{array}$} & \multicolumn{2}{c|}{ Enablers } & \multicolumn{2}{c|}{ Competency } & \multicolumn{2}{c|}{ Deployment } & \multicolumn{2}{c|}{ Governance } \\
\hline & A & B & A & B & A & B & A & B & A & B \\
\hline Level 1 Impromptu & & & & & & & & & & \\
\hline Level 2 Solo & & & $*$ & $*$ & $*$ & $*$ & $*$ & & & \\
\hline Level 3 Ensemble & $*$ & $*$ & & & & & & $*$ & $*$ & $*$ \\
\hline Level 4 Symphony & & & & & & & & & & \\
\hline
\end{tabular}

Regarding the first dimension, vision and strategy, analysed companies are on level 3 (Ensemble). This score implies that they know about the capability of PA, yet they have not formulated enterprise vision and strategy for using predictive analytics as a valuable asset for the company as a whole. Although some employees in separate departments have an analytics vision, yet there is no single formulated analytics strategy, even for that department. The achieved level is relatively high and can be a boost for achieving higher level on other dimensions.

The maturity of the analysed companies for the second dimension - enablers is on level 2 (Solo). This implies that separate business departments may work together with innovation or business intelligence units, yet there is almost no data exchange. While discussing this 
dimension with the managers-respondents, it was obvious that they are not satisfied with the alignment of the processes.

The third dimension is called competency. Analysed companies in our research are on level 2 of maturity. This implies that some business units, individual competency may exist, but it is not used widely on a regular basis. The reported level is in correlation with the reported level of the dimension enablers, and the silo thinking is still an obstacle in this companies for performing predictive analytics and monetizing its results.

For the fourth dimension - deployment, the answers from the interview are more dispersed. This means that company A is on the second level of maturity and company B on the third. Level 2 (Solo) means that in company A integration with the business information systems is manual. For company B which is on level 3 (Ensemble), this score shows that the analytics is integrated with decision-making systems. For both companies, the predictive analytics model output is not yet integrated with business intelligence systems, decision-making systems and business information systems.

The last dimension (governance) for both companies shows level 3 of maturity. This level, Ensemble, means that business unit level governance in both companies exist but, there is still a limited enterprise-level governance.

According to the results, the overall level of predictive analytics maturity is set between levels 2 and 3 for analysed companies. Although both companies are doing well on maturity journey, there is an evident difference in the maturity of the fourth dimension - deployment.

The PAMFA can serve as a plan for guiding the organisation to achieving its predictive analytics objectives. This framework is designed not only to identify the current level of analytical maturity but also to discover the organisation's Ideal Analytics Maturity Level (IAML) (Capgemini, 2012).

The limitation of the research methodology is the subjectivity that is expected in assigning the levels by the managers-respondents. Overestimating the levels of maturity is possible. However, this bias is present in every methodology of this type.

With respect to initially measurement, vision and methodology, broke down organizations are on level 3 (Ensemble). This score implies that they know about the capability of PA, yet they have not characterised and verbalised a venture vision and technique for utilizing it on a big business level. Increasingly exact, an investigation people in some speciality units have an examination vision, yet there is no enunciated examination methodology, notwithstanding for a solitary speciality unit yet. Vision is explained by individual speciality units, alongside the IT, who need to help the vision. The accomplished dimension is moderately high and can be a lift for accomplishing a more elevated amount on different measurements.

\section{CONCLUSION}

Organisations nowadays are focused on predictive analytics as a valuable tool to use data for achieving competitive advantage. The telecommunications sector in the country is one of the most advanced service sectors and hence represent a benchmark concerning the digital transformation. The results of our survey confirmed that telecommunications companies in the country understand the benefits of predictive analytics as a valuable source to gain a competitive advantage from data. The interview results confirm that organisations fall somewhere around level 2 or 3 for almost all dimensions. This survey results provide useful information needed to design a plan for migrating towards the higher levels of maturity. The road to achieve higher levels across all dimensions is hard, and it will take full management commitment in order to maintain competitive. This research is the first attempt to analyse organisational maturity in using predictive analytics in the country. Its originality derives from

the specific characteristics and development of telecommunications sector in the country and its importance. Knowing where an organization is on this journey will help managers/strategists to 
adopt Ideal analytics maturity level, i.e. the highest level that would enable organisations to derive maximum business benefits and achieve its strategic objectives. Further research can include companies from other industries in the country (finance, health) since the PAMFA can be used to measure and describe their predictive analytics efforts.

\section{REFERENCES}

Agency for Electronic Communications of the Republic of Macedonia. 2018. "Report on the development of the electronic communications market in the Republic of Macedonia for 2017." https://www.aek.mk

Capgemini. (2012). „Measuring Organizational Maturity in Predictive Analytics: the First Step to Enabling the Vision." https://www.capgemini.com

Ernst \& Young. (2015). "Global telecommunications study: navigating the road to 2020." https://www.ey.com

Grossman, Robert L. (2018). "A framework for evaluating the analytic maturity of an organization." International Journal of Information Management, 38: 45-51

Chen, L. \& Nath, R. (2018). "Business analytics maturity of firms: an examination of the relationships between managerial perception of IT, business analytics maturity and success", Information Systems Management,. 35(1): 62-77

Lismont, J., et al. (2017). "Defining analytics maturity indicators: A survey approach." International Journal of Information Management, 37 (3): 114-124

McKinsey Global Institute. (2016). "The Age of Analytics: Competing in a Data-Driven World.“ https://www.mckinsey.com

Mishra, N. \& Silakari, S. (2012). "Predictive Analytics: A Survey, Trends, Applications, Opportunities \& Challenges." International Journal of Computer Science and Information Technologies, 3 (3): 4434- 4438

Morabito, V. (2015). "Big Data and Analytics: Strategic and Organizational Impacts." Springer

Ransbotham, S. \& Kiro, D. (2018). "Using Analytics to Improve Customer Engagement, Findings from the 2018 Data \& Analytics Global Executive Study and Research Report." MIT Sloan Management Review, https://www.sloanrieview.mit.edu

Stoughton, J. (2018). "Turning Data Into Insights: How Digitization Creates New Opportunities For The Telecommunications Industry." https://www.digitalistmag.com

Trenevska Blagoeva, K., Josimovski, S., Mijoska, M. \& Jovevski, D. (2018). "Determinants of analytics usage to improve customer engagement in chosen Macedonian companies." Knowledge - International Journal, 22(1): 187-192.

Valdez-de-Leon, 0. (2016). "A Digital Maturity Model for Telecommunications Service Providers", Technology Innovation Management Review, 6 (8): 19-32

https://www.digitalistmag.com.

https://www.forbs.com

https://www.gartner.com

https://www.infoworld.com

https://www.predictiveanalyticstoday.com

https://www.statista.com

\begin{tabular}{l|l} 
Article history: & Received: May 16, 2019
\end{tabular}

Accepted: June 21, 2019 